\title{
Trends and Perspectives in the Design of Mobile Wood Chippers
}

\author{
Raffaele Spinelli, Enrico Marchi
}

\begin{abstract}
Mobile wood chippers represent a mature technology now available in a wide range of sizes and configurations. Different types exist, but the most widespread are disc and drum chippers. The latter have enjoyed wider popularity in recent years because they are best suited to processing logging residue and other low-quality wood. Drum chippers can be fitted with screens, designed to re-circulate oversize particles. In general, industrial chippers offer high productivity and high fuel efficiency, especially if settings are properly adjusted. Chippers are highmaintenance equipment and require proper care. Maintenance cost increases with machine age and can be predicted quite accurately, and so can chipping productivity and cost. Reliable models exist for estimating both maintenance cost and productivity, based on dedicated userentered assumptions. All things being equal, there are no substantial productivity and maintenance differences between tractor-powered and independent-engine chippers.
\end{abstract}

Keywords: biomass, comminution, efficiency, energy

\section{Introduction}

The production of renewable energy is the fundamental prerequisite for sustainable development of human civilization (Ramos Pires Manso and Bashiri Behmiri 2013). With a great sense of responsibility, many countries have made a formal commitment to increase the proportion of renewable energy used by their citizens and companies. To achieve this goal, national governments have enacted important legislation to encourage the production of renewable energy, including subsidies, contributions and tax relief for producers (Stupak et al. 2007). Renewable energy production has quickly become a good business, as evidenced by the many initiatives that have emerged in recent years (Kraussman et al. 2008).

Woody biomass is one of mankind's earliest energy sources (Tillman 1978) and today it still plays an important role in energy production in many countries. In the last five decades, over half of the global wood removal was classified as »wood fuel (FAO 2016).

Nowadays, the biomass sector seems to have the greatest potential for expansion, and could grow larger and faster than all the others (Asikainen et al. 2008). The production of energy biomass could lift an agricultural world that has been in crisis for many years, offering new perspectives to farmers and forest owners: the challenge lies in mobilizing this resource at competitive cost (Eriksson et al. 2006).

Wood chips can be produced from waste material by relatively small companies. However, chipping is not such a simple operation, and much technical knowledge is needed for efficient implementation (Anderson and Mitchell 2016).

The term chipping means just turning wood elements into small fragments (or chips) using sharp tools. Most commonly, chips have a length between 2 and $5 \mathrm{~cm}$, a maximum width of about $2 \mathrm{~cm}$ and a thickness of a few millimeters.

The aim of this review is to summarise, analyse and discuss chipping technology issues in order to identify future trends and perspectives of their development and design.

\section{Advantages and Disadvantages of Wood Chipping}

Wood chipping offers three main advantages, and namely:

$\Rightarrow$ advantage 1 - Chipping increases the surface-tovolume ratio of bio-fuels so as to accelerate 
chemical reactions, such as combustion. Wood chips burn better than wood logs, which explains why woodchip boilers are more efficient and emit less pollutants into the air than traditional stoves. For that reason, woodchip systems can easily use wood species that are generally rejected by traditional users because they produce too much soot if used in conventional chimneys (Spinelli et al. 2011a)

$\Rightarrow$ advantage 2 - Chipping dramatically increases wood handling properties. By turning elements of disparate shape and size into small and homogeneous fragments, chipping allows easy flow on any type of conveyors and better packing in transportation vehicles and storage sites (Stampfer and Kanzian 2006). In particular, the bulk density of chips is commonly between 300 and $400 \mathrm{~kg} \mathrm{~m}^{-3}$, while the density of loose residues rarely exceeds $150 \mathrm{~kg} \mathrm{~m}^{-3}$ (Spinelli et al. 2007). Therefore, handling bulk waste is an inefficient operation, which only makes sense when it is carried out over very short distances (Björheden 2008, Rawlings et al. 2004). If logging residues have to be transported over distances of more than a few kilometres, the cost of the operation becomes too high because the vehicles are unable to load a sufficient quantity of product, given its low bulk density (Spinelli et al. 2014a). At a density of $150 \mathrm{~kg} \mathrm{~m}^{-3}, 15 \mathrm{t}$ of branches are enough to fill a $100 \mathrm{~m}^{3}$ van, which should carry a load of at least $25 \mathrm{t}$. In short, small-sized even-shaped chips behave almost like a fluid, flowing in ducts and on conveyors and making the best use of all the space available

$\Rightarrow$ advantage 3 - Last but not least, chipping allows more tree mass to be recovered, including those tree components that are too small or malformed to be transformed into a conventional log sort (Asikainen and Pulkinen 1998). Much of the top and branch material cannot be processed into roundwood or firewood, but can still be chipped instead of being abandoned in the forest. Chipping this material not only increases the product yield per hectare, but also solves the problem of managing logging waste, otherwise piled and/or burned at a considerable cost (Jernigan et al. 2013), especially in fire-prone environments.

On the other hand, chipping also presents some disadvantages that constitute the other side of the coin.

$\Rightarrow$ disadvantage 1 - Fresh wood chips do not store well: the large surface-to-volume ratio that speeds up industrial conversion, also favours microbial attack. As the exposed surface is dramatically increased, microorganisms proliferate and »devour « the biomass. The result is a loss of dry matter that is between 2 and over $4 \%$ per month, on average (Barontini et al. 2014, Yingqian and Fei 2015). This process develops heat, which is the main indication of the phenomenon improperly called »fermentation «.

$\Rightarrow$ disadvantage 2 - The »fluidisation « effect of chipping is only effective if the particles are relatively small and homogeneous. The presence of chips with variable size and shape favours the formation of structures that hinder easy flow. These structures are formed most often inside ducts or near the discharge of containers, leading to the phenomenon called »bridging ", which is the source of many blockages (Jensen et al. 2004).

$\Rightarrow$ disadvantage 3 - A further disadvantage of chipping is the need for specialised machinery, which is generally expensive and has high fuel consumption (Yoshioka et al. 2006). Although the energy balance is always very favourable, fuel can be one of the main cost items, and the continuous increase in diesel prices is one of the main causes of concern for those who operate a chipper. Depending on the case, fuel represents about one third of the total chipping cost (Spinelli et al. 2019).

All the above makes it clear how important it is to acquire all the technical knowledge that allows efficient chipping, in order to reduce production cost, improve chip quality and facilitate subsequent handling and storage.

This is especially true when chips are produced from forest residues rather than sawmill residues. In fact, the latter is considered a waste and is available in large quantities, concentrated in sawmills near the main roads, resulting in a very low cost of production, since the transformation process requires only the chipping and transportation to the conversion plant. Furthermore, sawmill residues have a lower water content than forest chips and contain a greater quantity of fibre, as they are the by-product from the processing of logs that have already been stripped of their tops and branches. On the other hand, the recurrent crises in the wood sector cause a constant fluctuation in the availability of sawmill waste, and many sawmills are now organised to transform and market their own waste, anyway. For these reasons, the primary forest sector remains the source of wood chips with the greatest capacity for expansion, and it is there that efforts should be concentrated (Van Belle et al. 2003). 
However, economic margins are rather limited and it is important to know how to reduce chip production cost, while increasing chip value through the improvement of product and service quality.

\section{Chipper Types}

The cutting system is at the heart of the chipper, and it is what ultimately determines both the productivity of the operation and the quality of the product. All chippers are designed to push a sharp tool - the knife - against the wood to be processed, in order to detach chips of set dimensions (Stokes et al. 1987). To that end, one or more knives are mounted on a rotating device that gives them the speed and force necessary to carry out the work. The dynamics of the chipping process are quite complex, especially because of the anisotropic character of the wood, which has different properties depending on the direction in which it is engaged. Furthermore, several variables interact in an unexpected manner in the wood chipping process (Uhmeier 1995). However, the chipping process can be assimilated to that of planing, at least in general terms.

Depending on the type of rotating device, one can describe three main chipper types: disc chippers, drum chippers and cone-screw chippers.

\subsection{Disc Chippers}

In this case the cutting device consists of a heavy flywheel carrying two, three or four knives arranged in radial positions (Twaddle and Watson 1992). Wood

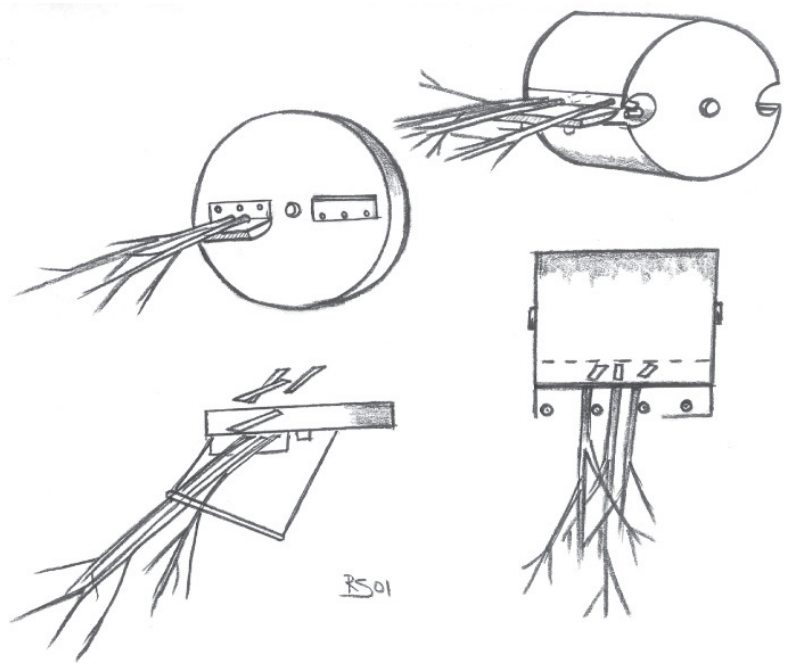

Fig. 1 Schematic representation of a disc chipper (left) and a drum chipper (right) is pushed against the rotating disc at a slight angle, so that the knives can cut thin slices off it (Fig. 1). Slots placed right under each knife allow wood chips to pass through the disc towards a blower, which throws them out of the machine through an ejection tube. An adjustable stop acts as an anvil (or counter-knife) and supports the action of the knives (Papworth and Erikksson 1966).

\subsection{Drum Chippers}

Drum chippers use a massive horizontal steel cylinder that revolves around its own axis (Fig. 1). The knives are mounted on the outer drum surface, in a tangential position. The number of knives depends on the manufacturer and varies from 1 to more than 20 . In principle, two configurations can be distinguished: one in which each individual knife covers the entire width of the drum, and one in which it covers only a portion of it. In the latter case, the drum will be equipped with a greater number of knives arranged in staggered positions, so that the entire surface being processed is still covered, albeit not all at the exact same time. Basically, each full revolution of the drum will result in many small »bites «, instead of one or two big »bites«. The advantage of using staggered knives is above all in the possibility of limiting the cost of any damage: in fact, critical damage is generally punctual - i.e. it occurs over a width of a few centimetres - but in that case the whole knife must be replaced, and the cost of the knife has to be proportional to its size. Therefore, the damage of a few centimetres on a full width knife still requires the replacement of the entire knife, with a much higher cost than that of a smaller knife. As their disc counterparts, drum chippers are also equipped with an anvil, which is necessary to exert a clean shear action.

Drums can be opened or closed. An open drum is constituted by a series of massive steel discs applied to a central axis, with the knife holders fixed in the spaces between the discs. On the contrary, a closed drum consists of a complete cylinder, with recesses (or pockets) carved right under the knives so that the cut wood is engulfed into the pocket and moved to the blower placed on the other end of the drum case, opposite the infeed opening.

In principle, there are no substantial differences between the performance of open drum chippers and closed drum chippers, at least as far as productivity and consumption are concerned. However, recent studies indicate that product quality is better for closed drum chippers when working with branches and other waste material, especially if the blades are worn. On the other hand, both solutions offer a very good 
product when working with new blades and/or good quality timber such as poles, logs, etc. (Spinelli et al. 2015a).

On drum chippers, it is possible to install a screen at the outlet, between the drum chamber and the blower, so that any oversized particles are trapped and returned to the chipper for further refining (Fig. 2). This possibility is common to all machines of European construction, while those of North American construction often lack it. For this reason, some European retailers have developed ad-hoc screen kits for retrofitting the American machines sold in Europe. Screens are not designed to set chip size: they only block oversize particles. Since they constrain the flow, screens determine a decrease in productivity and an increase in fuel use, both of which are proportional to screen size: the tighter the screen mesh, the stronger the impact (Eliasson et al. 2015).

Drum chippers are more productive than disc chippers, with a difference of about $10 \%$. Drum chippers, on the other hand, are less energy-efficient and consume about $20 \%$ more fuel than disc chippers per cubic meter of wood chips produced. The high energy efficiency of disc chippers may be related to their simpler

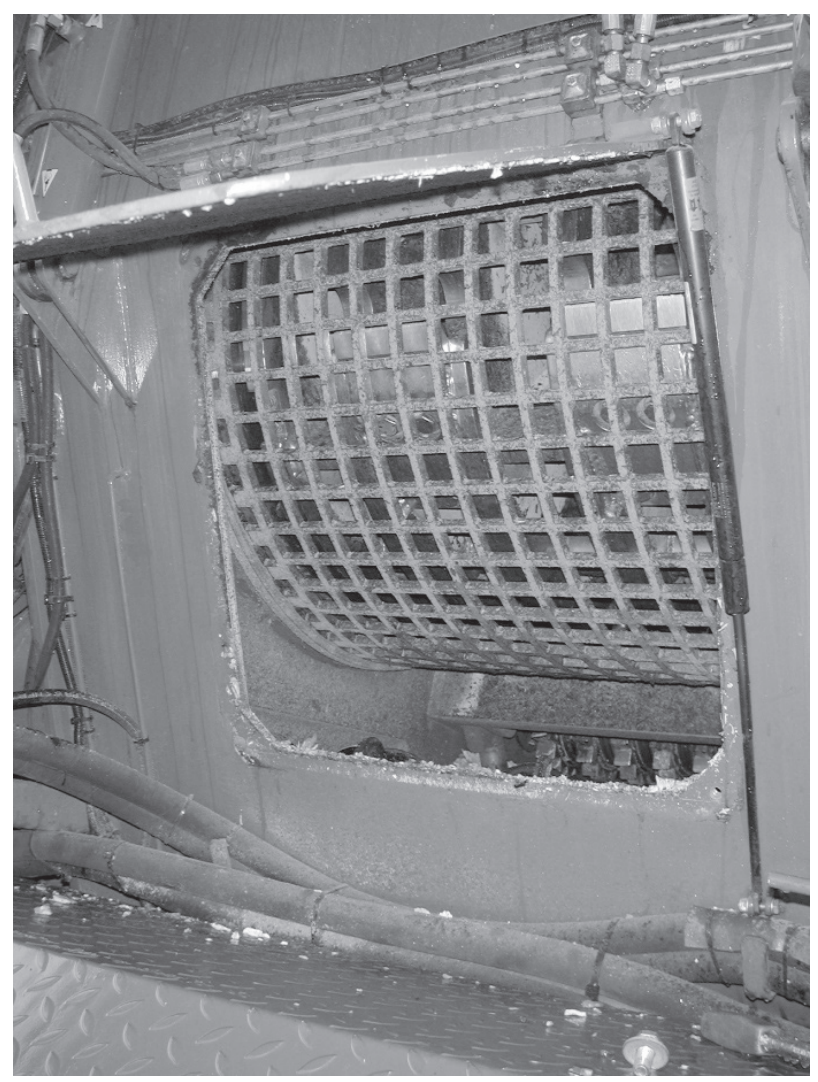

Fig. 2 The screen placed at drum case outlet design (Liss 1987). Drum chippers also tend to produce finer wood chips with a higher percentage of dust. This is partly due to the presence of screens, which contribute to fragmenting the woodchips and generating dust (Spinelli et al. 2013, Young and Hutton 1976).

\subsection{Cone-screw Chippers}

Cone-screw chippers are based on a steel cone with a single blade applied as a spiral along the cone surface. The material is grabbed by the blade and dragged into the chipping chamber where it is cut into pieces (Pottie and Guimier 1985).

The size of wood chips is determined by the pitch of the screw, i.e. the distance between two windings of the same spiral. Here too, an anvil (or counter-knife) is placed between the blade and the case containing the cone itself, to support the wood during cutting (Wegener and Wegener 2012).

This type of chipper has not met with great success, partly because it is quite difficult to use. In fact, the principle of operation of the conical screw implies two important limitations:

$\Rightarrow 1$ - the cone-screw pulls in the material to be chipped, without the need for a separate feeding system. This reduces both the cost and the weight of the machine, and is therefore an advantage. However, this mode of feeding implies that infeed speed cannot be modulated: if the machine is fed with too much material, there is no way of slowing down feeding and the machine will eventually choke (Wegener and Wegener 2014)

$\Rightarrow 2$ - the cone-screw has a much lower mass than a disc or drum, and a geometry that is not favourable to the accumulation of inertial forces. This means that the machine accumulates relatively little energy and is therefore unable to cope with a variable power demand. This combines with the limitation just mentioned above, making cone-screw chippers quite prone to choking if they are not handled with much care.

On the other hand, the cone-screw chipper produces the best quality wood chips among all types, provided that it is fed with logs of adequate size (Spinelli et al. 2006).

\section{Chipper Choice}

Mobile chippers are available in different models: carried on the three-point-hitch of a tractor, or mounted on a trailer or on a carrier - such as a truck, a forwarder or a purpose-built vehicle (Mihelič et al. 2015) (Fig. 3). 


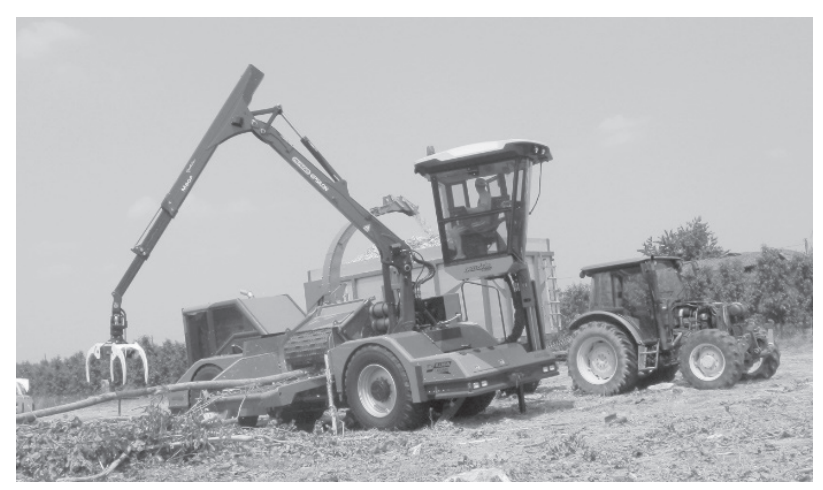

Fig. 3 A purpose-built versatile all-terrain chipper

In fact, the chipper can be just one component of a larger integrated machine, such as a chain-flail delimber-debarker chipper or a combined cutter-chipper, both of which are often used in fast-growing tree plantations of different types. For the sake of simplicity, this review will focus on chippers designed for chipping only, and tasked accordingly. Combined machines represent a separate case and have already been treated in other studies (Spinelli and de Arruda Moura 2019).

The chipper can be powered by the same engine of the tractor or the carrier, or be fitted with a separate independent engine. Generally, machines fitted with an independent engine are more powerful than tractor-powered machines, but the gap between the two is getting narrower, due to the development of ever more powerful tractors. Normally, tractor-powered chippers are less productive than independent-engine chippers, but that is because they are also less powerful: for the same power, productivity and efficiency do not seem to differ substantially between the two main types (Heikka and Piirainen 1981, Spinelli and Maganotti 2014c). The same is true for maintenance cost, as well (Spinelli et al. 2019).

The choice between different solutions depends very much on how often one needs to relocate, on the relocation distance and in general on the terrain characteristics found at the sites normally negotiated by the user (Yoshida 2019). If one is chipping directly in the forest and is treating relatively large plots of land, then a forwarder-mounted chipper is likely the best solution, because it is the most suitable for in-forest traffic. On the other hand, if relocation is frequent and chipping is performed at the roadside, then the user is better off with a truck-mounted chipper, especially if relocation distance exceeds a few kilometers (Marchi et al. 2011). Several manufacturers have developed compact industrial chippers for use whenever limited landing space represents a main constraint (Mihelič et al. 2018, Spinelli et al. 2015b).

In any case, an industrial-sized machine (power $>$ $200 \mathrm{~kW}$ ) is the only solution for those who process over $20,000 \mathrm{~m}^{3}$ of chips per year. Those who produce small quantities would better rely on an industrial contractor, unless the quantities processed are so small that contractor relocation cost would exceed the value of the chips. That is often the case when the lot size is below $100 \mathrm{~m}^{3}$ of chips: if so, probably the best thing is to use a small tractor-powered chipper. However, using a small chipper will cause a significant increase of chipping cost, often 2 or 3 times higher than the rate normally applied by industrial contractors (Yu et al. 2017).

\section{Maintenance}

Chippers do a very heavy job and are subject to high wear (Spinelli et al. 2017). For this reason, regular maintenance is essential to avoid failures and achieve a long service life. All machine devices must be properly checked and maintained, in particular the loader, engine, unloading system and knives.

Depending on how it is used, the loader may be subjected to heavy stress, and in some cases structural failure may also occur. The problem is that most loaders used with a chipper are not designed specifically for that use. This applies to separate self-propelled loaders detailed to assist a chipper as well as to built-in loaders, because the latter are often general-purpose models designed for generic loading tasks and mounted onto the chipper - but not designed with it. While loaders are normally designed for vertical lifting, feeding a chipper involves lateral effort, such as pulling logs out of a pile and thrusting them into the infeed opening.

As far as the engine is concerned, overheating seems to be the main problem. Chipping produces a large amount of dust, which inevitably settles on the cylinder liners. In summer, leaf fragments are deposited on the radiators and can cover them very quickly. At this point, if the engine has an automatic safety switch, it will switch off. Otherwise, the engine can overheat and burn the head seal. Worse still, the dust accumulated on the exhausts and cylinders can ignite. Fire can rapidly spread to the many grease and diesel spills, at which point the chipper is likely lost and a wildfire may spread out.

For this reason, it is advisable to equip all chippers with fire extinguishers, located within easy reach and 
close to strategic areas. Better yet, industrial chippers should be equipped with automatic fire extinguishing systems, covering all vulnerable areas and activated by heat build-ups. The simplest such system would use a pressurised extinguishing medium injected into a network of plastic tubes: once heat builds up near a tube, the tube will melt and release a jet of pressurised foam on the very hot spot that caused its melting.

In any case, during the hot season the operator should regularly switch off the chipper, take the compressor and clean the engine and radiators. This should always be done at the end of the work day, regardless of season. Wood dust on an overheated machine represents a very high risk, and before leaving the site the operator must take great care that everything is clean and the risk of fire has been minimised (Spinelli and Hartsough 2001).

The electrical system can fail due to incorrect use, excessive vibration or poor waterproofing. Electrical problems are more common on old machines - while new ones are much more reliable. However, it is better to check the seals and shock absorbers of the electrical boxes regularly. The operator should always have a wiring diagram at hand: damage is often minimal, but if one does not know how to repair it, expensive downtime will be incurred.

During the cold season, one should make sure that the chipping chamber and the woodchip evacuation system are completely empty before turning off the machine and leaving it for the night. In fact, if the chipper stays outdoors and the temperature is very cold, any wet wood chips that remain inside the machine can freeze, turning into a solid block. This will cause a lot of problems the following morning, when starting up: with the main systems jammed by frozen chips, the engine will stall as soon as the clutch is engaged. If that occurs, unblocking the machine will require much effort, and a solid iron bar. If available, hot water may also help. Needless to say, the batteries should be disconnected at the end of the work shift, especially during the cold season.

Recent studies indicate that repair and maintenance represent about $15 \%$ of the total chipper cost (Spinelli et al. 2019). As expected, maintenance cost increases over time, and the rate of increase follows approximately the same curve shape as found for most agricultural machines (Abdelmotaleb 1989). Normally, maintenance cost is expressed as total accumulated repair (TAR) and is referred to purchase price. In the specific case of chippers, the \% ratio between TAR and purchase price has been described by Spinelli et al. (2019) through the following equation (Eq. 1):
$\mathrm{TAR} /$ price $=$

$=3.408 \cdot 10^{-4} \cdot$ Hours $0.83+8.635 \cdot 10^{-5} \cdot$ Hours $\cdot$ Used

Where:

Hours total hours worked at the time of the estimate Used indicator variable: 0 if the chipper was bought new, 1 if the chipper was bought second-hand.

Knife cost represents the largest proportion of chipper maintenance cost.

\section{Knives and Anvil}

Knives are the soul of a chipper. There is no point in mounting a tight screen or feeding the machine with clean round wood if the knives are not sharp and properly adjusted. The number one requirement to ensure high productivity and good product quality is a good condition of the knives. When the knives no longer cut, they must be changed. Waiting longer means wasting time and money.

Knives are made of high-grade tool steel, or of structural steel with high-grade tool steel edges. Manufacturers generally use high-grade cold working alloy steel of different types, and typically 1.2631, A8 and D2 DIN grades. Knives are normally hardened to between 55 and 60 HRC (Rockwell scale).

During service, knives are generally sharpened with a wet sharpener, after removing them from the chipper. Knives can also be honed manually with a portable electric grinder, without removing them from the chipper (i.e. dry sharpening). The result is not as good as with a wet sharpener, because manual grinding is not accurate enough and it cannot restore a proper front angle. In fact, dry sharpening is normally used to improve knife performance on the fly, between two wet sharpening sessions. Dry sharpening was never meant to replace wet sharpening, but just to complement it (Spinelli et al. 2014b).

Regardless of sharpening technique, knives become shorter after each sharpening session, because grinding removes part of the knife material. For this reason, knife offset must be adjusted after sharpening. Knives must be moved forward, in order to maintain the correct clearance between knife and anvil. That is crucial for an efficient shearing action. Clearance is generally comprised between 0.5 and $0.8 \mathrm{~mm}$, and is checked with a spacer gauge. The anvil itself is made of high-grade steel similar to that used for knife manufacturing. Furthermore, the anvil edges can be layered with wear resistant alloy. Anvils are also subject to wear, and they are turned when their edge has a curvature radius of about $5 \mathrm{~mm}$. When all four sides 
are worn, then the anvil must be discarded. In turn, knives are discarded when they become too short for safe operation (Pottie and Guimier 1985).

The service life of knives depends on the type of wood processed and especially on its level of contamination with soil and stones. When wood is dragged on the ground rather than carried off it, contamination is higher and knife duration shorter. The opposite is true when the wood is forwarded or yarded, avoiding direct contact with the ground, or when chipping directly on the cut over, which makes skidding unnecessary. For the same reason, much care must be taken when piling wood before chipping. If this operation is performed with a bulldozer or the front blade of a skidder, soil is often mixed with the wood and it will end into the chipper causing rapid wear or even damage (Spinelli and Hartsough 2001).

The most serious damage is caused by stray iron, which is occasionally mixed with the wood. This can be a large nail, a shell splinter embedded in an old stem, or an iron post accidentally thrown into the timber pile. This material is generally rusty, brownish and quite difficult to make out from among wood elements. If iron enters the chipper, it gets stuck between the knife and the anvil, causing severe damage. In most cases, damage is contained within the knife and the supporting sandwich plates that clamp it in place. However, if all the retaining bolts in a sandwich plate are sheared, then the massive plate can be flung off inside the chipping chamber, generating severe damage. In the worst cases, repair cost can exceed 20,000€ per event (Spinelli and Magagnotti 2014d). That does not account for the production losses incurred during the prolonged machine downtime.

Against this eventuality, the best solution is to equip the chipper with a swing-away anvil type. This is quite common on stationary chippers, and a bit rarer on mobile chippers, which - paradoxically - are more at risk than stationary chippers. However, most modern mobile chipper models can be fitted with a swing-away anvil, as a series or optional component. Basically, a swing-away anvil is just an anvil mounted on a sliding (or swinging) support, fixed to the main body by calibrated shear bolts. If iron or other hard material accidentally enters the chipper, the calibrated bolts will shear and the counter-knife will slide downwards, clearing the way for the expulsion of the hard object before it can cause further damage. If deployment is successful, damage will be limited to one knife and the shear bolts, which must be replaced before returning the counter-knife to its original position. Obviously, it is necessary to use bolts, specially calibrated by the manufacturer, to avoid that the counter-knife

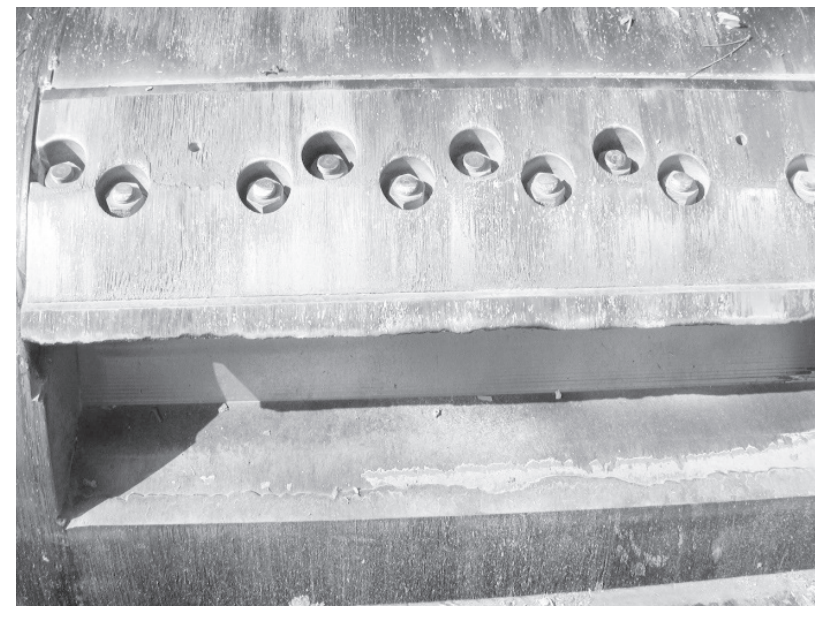

Fig. 4 Completely worn out knife, well past the recommended replacement time

blade jumps at the slightest impact, or that it remains in place until the damage becomes too severe.

If the chipper is properly fed and no stone or iron are thrown into it, then a set of new knives can process between 70 and 500 fresh tonnes of wood before requiring replacement (Fig. 4). A standard re-usable knife can be re-sharpened between 15 and 40 times, depending on knife type and the level of wear (Table 1). If the chipper uses multiple staggered knives, it is best to rotate the position of the knives between one sharpening and the next. That is done because the knives mounted in the centre of the drum work more than those in the lateral positions, and therefore incur a more intense wear. For this reason, their sharpening requires the removal of more material, and produces a greater shortening than that incurred by the knives in the lateral positions. Rotating the positions between one sharpening and the next allows the balanced wear

Table 1 Example of knife management cost

\begin{tabular}{|l|c|c|c|}
\hline & $n$ & Mean & Std. Dv. \\
\hline Price of knife set, $€$ & 3 & 550 & 87 \\
\hline Total work volume, $t$ fresh & 3 & 1770 & 412 \\
\hline Sharpening sessions, $n^{\circ}$ & 3 & 16.7 & 2.9 \\
\hline Sharpening sessions, $€ /$ session & 3 & 29.7 & 13.0 \\
\hline Work volume sharp knife, t fresh & 3 & 103 & 35 \\
\hline Investment cost, $€ / t$ fresh & 3 & 0.32 & 0.08 \\
\hline Sharpening cost, $€ / t$ fresh & 3 & 0.27 & 0.09 \\
\hline Total cost, $€ / t$ fresh & 3 & 0.59 & 0.08 \\
\hline
\end{tabular}


of the entire set of knives and a longer service life. Besides, that maintains better drum balance, since an irregular wear implies that some knives become shorter and lighter than the others.

An interesting alternative to conventional re-usable knives are disposable knives, now offered by several manufacturers. These knives are shorter and cheaper than their re-usable counterparts, since they do not need to account for the shortening caused by grinding, even though many operators usually resharpen them at least once before disposal. Disposable knives offer several advantages: first, simplified handling, since they do not require further sharpening and the eventual re-adjustment of knife offset during assembly: at least in theory, new knives of the same length are always mounted; second, their very low cost, which allows minimising losses in case of damage; finally, their longer relative service life, as studies report that one change of disposable knives lasts longer than one of conventional re-usable knives. It is not clear why that would be the case, but one reasonable assumption is that the shorter length of the disposable knife type leads to less vibration, or also that their short-term use prevents metal degradation due to the accumulation of fatigue or to repeated heating events over more sharpening cycles. In any case, recent studies indicate that a change of disposable knives can process about $50 \%$ more product than a change of conventional knives. What is more, several studies agree in indicating that the cost of knife management can be reduced from a third to a half through the use of disposable knives (Kjerulf and Jonson 1987, Scollard 1980, Spinelli and Magagnotti 2014d).

The anvil lasts much longer than the knives. It normally has a square section with four working faces, and it can be »turned « up to four times as each working face wears down. A single face can easily process up to 2500 tons of wood, and therefore a square counter knife would process up to 10,000 tons of wood chips.

The signs that the knives need changing are quite obvious. First of all, the chipper no longer pulls the material in, and the operator needs to push it into the infeed opening with some force, using the loader. Second, the chips are smaller, more irregular and fragmented: they look more like splinters than cleanly-cut slices. Finally, productivity drops and fuel consumption increases. These changes can be quite notable.

\section{Productivity and Fuel Consumption}

Planning chipping operations requires an accurate estimate of their production potential. A professional chipper operator has the capacity to estimate both the net productivity of his chipper and the gross daily production of his chipping operation. The first is measured net of all work interruptions due to maintenance, preparation, interference, etc. The second, on the other hand, represents the value actually reached during the day, and is the real value, which includes the effect of preparation, maintenance, interference, etc.

The net productivity of a chipper depends essentially on technical factors, including above all the power of the chipper and the size of the wood fed into it. Productivity grows along with chipper power and with the size of the single piece to be chipped - within the capacity limits of the machine, of course (Spinelli and Hartsough 2001). In contrast, it is more difficult to determine the effect of tree species (Abdallah et al. 2011), wood moisture content (Spinelli et al. 2011) and tree form (Spinelli and Magagnotti 2010).

All these factors being equal, productivity is also influenced by cut length, drum rotational speed, knife wear and the size of the screen eventually applied to the chipper (Krajnc and Dolsak 2013, Ismail and Ghazy 2016, Spinelli and Magagnotti 2013).

As far as the cut length is concerned, three reference levels can be considered, depending on the type of wood chips to be produced. The cutting length can be set to $7 \mathrm{~mm}$ to produce micro-chips for the smallest boilers, to $20 \mathrm{~mm}$ to produce fine chips for small district heating plants, or to $40 \mathrm{~mm}$ to produce coarse chips for gasification. If one takes $20 \mathrm{~mm}$ as the reference cut length, then productivity will decrease by about one third if one switches to the shorter length $(7$ $\mathrm{mm}$ ) and will increase by about $15 \%$ if one switches to the longer length (40 $\mathrm{mm}$ ) (Facello et al. 2013).

Knife wear has an even more pronounced effect. When the knives are worn out, productivity is halved compared to the values achieved with new knives (Grönlund and Eliasson 2013). For this reason, it is best to change the knives in due time, because performance quickly declines as they lose their sharpness.

The interposition of a screen slows down the flow of wood chips and causes a drop in productivity, which is all the more marked when the screen mesh is narrower (Choi et al. 2019, Eliasson et al. 2015, Nati et al. 2010). The loss of productivity is quite significant, and is around $25 \%$ when switching from a wide mesh screen (e.g. $60 \times 240 \mathrm{~mm}$ ) to a medium mesh screen $(60 \times 40 \mathrm{~mm})$. In general, it is advisable to use a screen as wide as possible, within the limits imposed by customer specifications and the type of material to be chipped.

Finally, performance can vary considerably depending on the individual capabilities of the machine 
operator. The best operators can achieve a productivity that is $30 \%$ higher than the reference average, while the least capable operators can remain below this average by the same margin $(-30 \%)$.

In addition to purely technical factors, a chipper gross productivity also depends on organizational factors that can heavily affect the entire operation (Ghaffariyan et al. 2013). In fact, the technical potential of a machine can be fully exploited only if the process is well organised, and downtime minimised. Most downtime is caused by mechanical breakdowns, lack of material to be chipped, or lack of means to receive the wood chips (Spinelli and Visser 2009). These factors cause interruptions in the work process and reduce actual productivity. A certain amount of downtime is inevitable, and the operator's ability is rather in avoiding predictable delays through timely maintenance and rational site planning (Zamora et al. 2013).

Under average working conditions, the following productivity can be expected for different machine types.

$\Rightarrow$ chipper driven by the PTO of a $100 \mathrm{~kW}$ tractor, and manually powered by two people: approx. 2 fresh t/gross hour, inclusive of all delays; approx. 121 diesel/gross hour

$\Rightarrow$ chipper driven by the PTO of a $200 \mathrm{~kW}$ tractor, and fed by a loader: 5-7 fresh t/gross hour; consumption: about 201 diesel/gross hour

$\Rightarrow$ industrial chipper with $350 \mathrm{~kW}$ independent engine, fed by a loader: $15-25$ fresh t/gross hour; consumption 30-35 1 diesel/gross hour.

These are general reference values, and may vary with the type of material and the organisation of the site (Ghaffariyan 2019). Operators can obtain reasonably accurate estimates of productivity and costs using the ChipCost.xls model, which is included in the Electronic Supplementary Materials annexed to this article (Spinelli and Magagnotti 2010).

\section{The Effect of Knife Wear on Chipper Efficiency}

Wear occurs in the knife's edge, which is in direct contact with the processed material. Wear is the result of a complex combination of mechanical, thermal, electrical and chemical processes (Moiseev 1981). Their interaction is not fully understood, but the mainstream opinion is that heat development in the cut interface may explain most of the wear of a cutting tool (Blachnio 2009). The high concentration of mechanical energy in the edge results in high pressure and significant tensions. These are transformed into thermal energy, which the processed material cannot dissipate easily, being a very poor conductor (Korobkov 1974). Heat, pressure and abrasion determine an increase in the blade front angle, leading to inefficient shear action (Obreshkov 1996). Then, the only remedy is to restore blade angle through periodical sharpening.

After sharpening, knife angles must be back to the original values of about $30^{\circ}$ for the front angle and $35^{\circ}$ for the rear angle. Angles are checked with simple protractors, with a tolerance between $+10^{\prime}$ and -30 ' minutes of arc. The quality of edge sharpening should be checked visually with 10x magnifying glasses. The edge must be sharp all along, and it must be free from cracks, dents, deformations, stain, etc.

Knife wear has a strong impact on productivity, fuel consumption and product quality. In particular, knife wear determines a sharp increase of oversize fragments, which is mitigated through the application

Table 2 The effect of knife wear on chipper performance

\begin{tabular}{|c|c|c|c|c|c|c|c|}
\hline Study & Worn after & Productivity & Fuel use & Oversize & Fines & Function & Reference \\
\hline 1 & 100 to $300 \mathrm{gt}$ & $-15 \%$ & $+50 \%$ & $+200 \%$ & $+10 \%$ & Yes & Nati et al. 2010 \\
\hline 2 & $50 \mathrm{t} \mathrm{DM}$ & $-37 \%$ & $+27 \%$ & $\mathrm{NA}$ & $\mathrm{NA}$ & Yes & Spinelli and Magagnotti 2012 \\
\hline 3 & $\mathrm{NA}$ & $-50 \%$ & $+140 \%$ & $+100 \%$ & $+80 \%$ & No & Facello et al. 2013 \\
\hline 4 & $100 \mathrm{gt}$ & Nsd & $+20 \%$ & $\mathrm{nsd}$ & $+100 \%$ & No & Manzone and Spinelli 2013 \\
\hline 5 & $\mathrm{NA}$ & $-33 \mathrm{to}-75 \%$ & +25 to $90 \%$ & $+300 \%$ & $+100 \%$ & No & Spinelli et al. 2013 \\
\hline 6 & NA & $-30 \%$ & $+39 \%$ & NA & NA & No & Spinelli et al. 2014 2014 \\
\hline 7 & $245 \mathrm{gt}$ & $-19 \%$ & NA & $+170 \%$ & $+100 \%$ & No & Spinelli et al. 2015 \\
\hline 8 & $350 \mathrm{~m}^{3}$ loose & $-33 \%$ & NA & NA & NA & Yes & \\
\hline
\end{tabular}

Notes: $\mathrm{gt}=$ green ton; $\mathrm{DM}=$ Dry matter; Fuel use $=$ I per unit product $\left(\mathrm{t}\right.$ or $\left.\mathrm{m}^{3}\right)$; Oversize $=$ chips longer than $100 \mathrm{~mm}$; Fines $=$ chips smaller than $3.5 \mathrm{~mm}$ 
of resizing screens or piece breakers. However, these additional devices may determine a further decrease of productivity and fuel efficiency (Nati et al. 2010). Confronted by such a complex issue, operators replace worn knives based on their subjective perception of performance decay (Spinelli and Hartsough 2001). In most cases, knives are replaced when they are no longer able to produce viable chips. That allows maximising knife service life, to the benefit of reduced knife maintenance cost (Spinelli and Magagnotti 2014b). However, it is uncertain whether the savings accrued by maximising knife service life can offset the additional cost incurred through decreased productivity and fuel efficiency.

Table 2 offers a general overview of the results of 8 recent studies that investigated the effects of knife wear on chipper productivity, fuel efficiency and chip quality. Knife wear results in a marked decrease of chipper productivity and an even higher increase of fuel consumption per unit product. Knife wear also results in a dramatic increase of both oversize particles and fines. Figures are somewhat variable, and depend

Table 3 A view of the calculator interface, with a typical example

\begin{tabular}{|c|c|c|c|c|c|c|}
\hline \multicolumn{3}{|c|}{ Chipper performance data } & & \multicolumn{3}{|c|}{ Knife maintenance data } \\
\hline \multicolumn{2}{|c|}{ Initial productivity, t/h } & \multicolumn{2}{|l|}{35} & \multicolumn{2}{|l|}{ Cost of a set, $€$} & 600 \\
\hline \multicolumn{2}{|c|}{ Initial Fuel use, L/t } & \multicolumn{2}{|l|}{1} & \multicolumn{2}{|c|}{ Cost of sharpening, $€$} & 30 \\
\hline \multicolumn{2}{|c|}{ Machine cost, €/h } & \multicolumn{2}{|l|}{200 excluding fuel } & \multicolumn{2}{|l|}{$\mathrm{N}^{\circ}$ sharpenings } & 16 \\
\hline Fuel cost, $€ / L$ & & 1.4 & & \multicolumn{2}{|c|}{ Cost of replacing, $€$} & 20 \\
\hline \multicolumn{7}{|c|}{ Results } \\
\hline $\begin{array}{l}\text { Knife wear, t } \\
\text { worked }\end{array}$ & Productivity, t/h & Fuel, L/t & Chipping, $€ / t$ & Knife cost, $€ / t$ & Total cost, $€ / \mathrm{t}$ & $\begin{array}{l}\text { Productivity, \% } \\
\text { change of initial }\end{array}$ \\
\hline 10 & 35.0 & 1 & 7.1 & 8.8 & - & - \\
\hline 20 & 34.3 & 1.0 & 7.3 & 4.4 & - & - \\
\hline 30 & 34.0 & 1.1 & 7.4 & 2.9 & 10.3 & $-3 \%$ \\
\hline 40 & 33.6 & 1.1 & 7.5 & 2.2 & 9.7 & $-4 \%$ \\
\hline 50 & 33.3 & 1.1 & 7.6 & 1.8 & 9.3 & $-5 \%$ \\
\hline 60 & 32.9 & 1.1 & 7.7 & 1.5 & 9.1 & $-6 \%$ \\
\hline 70 & 32.6 & 1.2 & 7.8 & 1.3 & 9.0 & $-7 \%$ \\
\hline 80 & 32.2 & 1.2 & 7.9 & 1.1 & 9.0 & $-8 \%$ \\
\hline 90 & 31.9 & 1.2 & 8.0 & 1.0 & 8.9 & $-9 \%$ \\
\hline 100 & 31.5 & 1.2 & 8.1 & 0.9 & 8.9 & $-10 \%$ \\
\hline 110 & 31.2 & 1.2 & 8.2 & 0.8 & 9.0 & $-11 \%$ \\
\hline 120 & 30.8 & 1.3 & 8.3 & 0.7 & 9.0 & $-12 \%$ \\
\hline 130 & 30.5 & 1.3 & 8.4 & 0.7 & 9.0 & $-13 \%$ \\
\hline 140 & 30.1 & 1.3 & 8.5 & 0.6 & 9.1 & $-14 \%$ \\
\hline 150 & 29.8 & 1.3 & 8.6 & 0.6 & 9.2 & $-15 \%$ \\
\hline 160 & 29.4 & 1.4 & 8.7 & 0.5 & 9.2 & $-16 \%$ \\
\hline 170 & 29.1 & 1.4 & 8.8 & 0.5 & 9.3 & $-17 \%$ \\
\hline 180 & 28.7 & 1.4 & 8.9 & 0.5 & 9.4 & $-18 \%$ \\
\hline 190 & 28.4 & 1.4 & 9.0 & 0.5 & 9.5 & $-19 \%$ \\
\hline 200 & 28.0 & 1.4 & 9.2 & 0.4 & 9.6 & $-20 \%$ \\
\hline 210 & 27.7 & 1.5 & 9.3 & 0.4 & 9.7 & $-21 \%$ \\
\hline
\end{tabular}


on study conditions - especially machine type, feedstock type and measurement method. Instrumental studies designed to isolate single effects (Facello et al. 2013, Spinelli et al. 2013) report an even stronger impact compared with studies conducted under real operational conditions.

The amount of wood processed before changing knives is most variable, because of the wide differences between feedstock types and the unpredictable contamination levels - the latter being typically erratic. The studies in the table indicate that a set of new knives will need sharpening after working between 100 and 300 tonnes of green wood, or between 165 and $620 \mathrm{~m}^{3}$ of loose chips (Spinelli et al. 2015). These figures are fully compatible with the 50 to 300 fresh tons bracket reported by Spinelli and Hartsough (2001) or the 300 to $1300 \mathrm{~m}^{3}$ of loose chips reported by Spinelli and Magagnotti (2014a).

Despite the large variation in the data, one may obtain a reasonably clear picture of the effects of knife wear. Furthermore, three of the above-mentioned studies also offer specific functions designed to predict performance variations (i.e. productivity and fuel use changes) as a function of knife wear, as described by the amount of wood chipped since the knives were installed. Obviously, the estimated chipping cost will increase with the number of fresh tonnes processed with the same set of knives, due to the performance decline consequent to knife wear. However, knife management cost will decrease with the number of tons processed between two sharpening sessions (Spinelli and Magagnotti 2014, Spinelli et al. 2014c).

Based on this information one can try to estimate the trade-offs between extended service life and decreasing chipper efficiency in the form of a minimum cost curve. All functions reported in the existing studies are linear and therefore the variation caused by wear can be expressed as a percent of the original starting value (the intercept). This way one can build a relatively flexible calculator, which users can adapt to the actual starting productivity and fuel use of their own machines, as fitted with new knives. Such calculator was produced within the scope of the INFRES EU project and is included in the electronic supplementary materials annexed to this article.

When users enter their own estimates for the initial productivity and fuel consumption, the calculator estimates the corresponding productivity and fuel consumption values after working »n « tons of fresh wood with the same set of knives. The calculator also allows users to enter their own estimates for machine hourly cost (excluding fuel cost) and fuel price, which are used for estimating the mean chipping cost for the

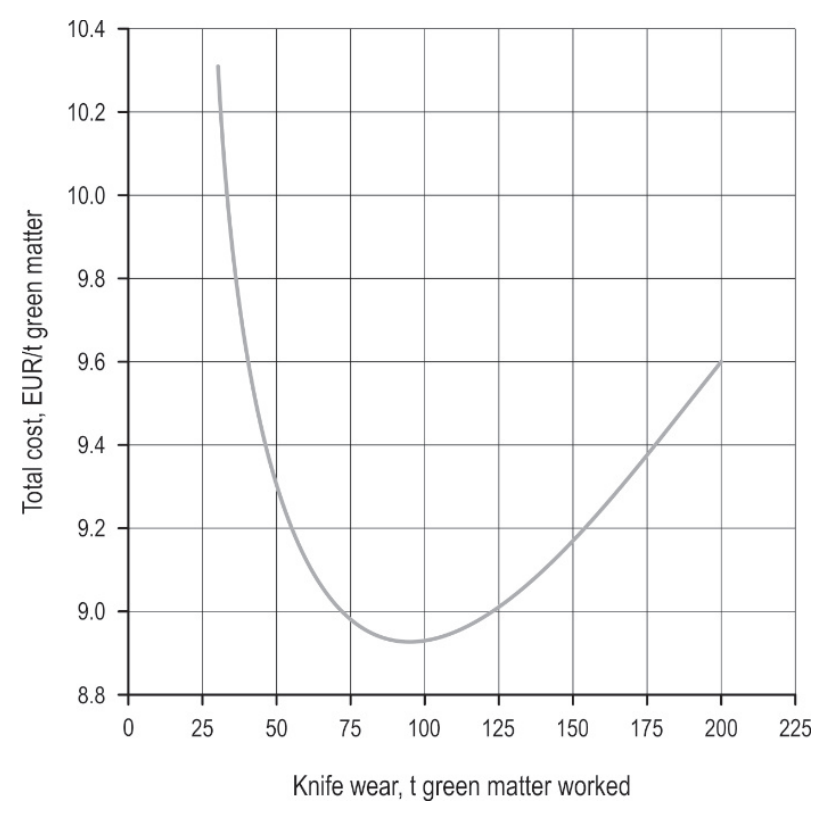

Fig. 5 Minimum cost graph for knife replacement calculated based on assumptions in Table 3

processing of »n « tonnes of fresh wood. Of course, the flexibility of the calculator is not unlimited. The calculator was developed based on data collected for industrial machines in the power class between 300 and $400 \mathrm{~kW}$. Under normal conditions, these machines have a productivity between 20 and $40 \mathrm{t}$ of fresh wood per hour. Therefore, the calculator is verified for a similar range of values, and should not be used for much larger or smaller machines: that would represent a dangerous extrapolation. Table 3 reports an example in the use of the calculator, while Fig. 5 shows the results in graphic form.

Changing knives takes between twenty minutes and an hour, all inclusive. The availability of an airpowered screwdriver makes all the difference. Disposable knives are quicker to change because no adjustments need to be made. Obviously, replacement time is proportional to the number of knives.

\section{Conclusions}

Purchasing an industrial chipper requires a significant capital investment, which makes expert management crucial - the more so, since the machine is a specialised piece of equipment designed for one specific task, and its cost cannot be spread over multiple job types. Mechanical competence alone is not enough to guarantee the success of a company dedicated to chipping, although it is a fundamental requirement. Chipper operators must also possess good planning 
skills. The production of wood chips requires specific knowledge of the entire process. Success depends on proper machine selection, rational work planning and careful choice of the market objectives. A company dedicated to the industrial production of wood chips should have a fairly powerful machine $(>200 \mathrm{~kW})$ and should install their machine on a carrier that is compatible with the main conditions of use. Proper setting adjustments and careful maintenance will do the rest.

\section{References}

Abdallah, R., Auchet, S., Méausoone, P.J., 2011: Experimental study about the effects of disc chipper settings on the distribution of wood chip size. Biomass and Bioenergy 35(2): 843-852. https://doi.org/10.1016/j.biombioe.2010.11.009

Abdelmotaleb, I., 1989: Repair and maintenance cost analysis of tractors and combines. PhD Thesis. Iowa State University, Ames, IA, USA, 163 p.

Anderson, N., Mitchell, D., 2016: Forest Operations and Woody Biomass Logistics to Improve Efficiency, Value, and Sustainability. Bioenergy Research 9(2): 518-533. https://doi. org/10.1007/s12155-016-9735-1

Asikainen, A., Pulkkinen P., 1998: Comminution of Logging Residues with Evolution 910R chipper, MOHA chipper truck, and Morbark 1200 tub grinder. Journal of Forest Engineering 9(1): 47-53.

Asikainen, A., Liiri, H., Peltola, S., Karjalainen, T., Laitila, J., 2008: Forest Energy Potential in Europe (EU27). Working Papers 69. Finnish Forest Research Institute, Joensuu.

Barontini, M., Scarfone, A., Spinelli, R., Gallucci, F., Santangelo, E., Acampora, A., Raida Jirjis, R., Civitarese, V., Pari, L., 2014: Storage dynamics and fuel quality of poplar chips. Biomass and Bioenergy 62: 17-25. https://doi.org/10.1016/j.biombioe.2014.01.022

Björheden, R., 2008: Optimal point of comminution in the biomass supply chain. In: Editor Talbot, B., Proceedings of the Nordic-Baltic Conference on Forest Operations, 23-25 September, Copenhagen. Copenhagen, Denmark, Danish Forest and Landscape 28-30 p.

Blachnio, J., 2009: The effect of high temperature on the degradation of heat resistant and high temperature alloys. Solid State Phenomena 147-149: 744-751. https://doi.org/10.4028/www. scientific.net/SSP.147-149.744

Choi, Y.-S., Cho, M.-J., Paik, S.-H., Mun, H.-S., Kim, D.-H., Han, S.-K., Oh, J.-H., 2019: Factors Affecting the Chipping Operation Based on the Screen Size of the Drum Chipper. Forests 10(11): 1029 https://doi.org/10.3390/f10111029

Eliasson, L., von Hofsten, H., Johannesson, T., Spinelli, R., Thierfelder, T., 2015: Effects of sieve size on chipper productivity, fuel consumption and chip size distribution for open drum chippers. Croatian Journal of Forest Engineering 36(1): 11-18.

Ericsson, K., Nilsson, L., 2006: Assessment of the potential biomass supply in Europe using a resource-focused approach. Biomass and Bioenergy 30(1): 1-15. https://doi.org/10.1016/j. biombioe.2005.09.001
Facello, A., Cavallo, E., Magagnotti, N., Paletto, G., Spinelli, R., 2013: The effect of knife wear on chip quality and processing cost of chestnut and locust fuel wood. Biomass and Bioenergy 59: 468-476. https://doi.org/10.1016/j.biombioe.2013.07.012

FAO 2016: FAOSTAT database (available at www.fao.org/faostat/en/\#home), Rome.

Ghaffariyan, M., 2019: Short review on overview of forest biomass harvesting case studies in Australia. Silva Balcanica 20(1): 89-96. https://doi.org/10.6084/m9.figshare.8235401

Ghaffariyan, M.R., Spinelli, R., Brown, M., 2013: A model to predict productivity of different chipping operations. Southern Forests 75(3): 129-136. https://doi.org/10.2989/20702620.2013.8 16233

Grönlund, Ö., Eliasson, L., 2013: Effects of knife wear on the performance and fuel consumption for a drum chipper. Proceedings of the 2013 Formec Conference, September 30 to October 2, Stralsund, Germany.

Heikka, T., Piirainen, K., 1981: Power consumption of small chippers. Institutum Forestale Fenniae. Folia Forestalia 496.

Ismail, Z.E., Ghazy, M.I., 2016: Influence of drum chipper setting on the wood chips performance. Misr Journal of Agricultural Engineering 33(4): 1293-1312. https:/doi.org/10.21608/ MJAE.2016.97598

Jensen, P., Mattsson, J., Kofman, P., Klausner, A., 2004: Tendency of wood fuels from whole trees, logging residues and roundwood to bridge over openings. Biomass and Bioenergy 26(2): 107-113. https://doi.org/10.1016/S0961-9534(03)00101-6

Jernigan, P., Gallagher, T., Aulakh, J., Tufts, R., McDonald, T., 2013: Implementing residue chippers on harvesting operations in the Southeastern US for biomass recovery. International Journal of Forest Engineering 24(2): 129-136. https://doi.org/10.108 0/14942119.2013.798130

Kjerulf, E., Jonsson, J., 1987: Disposable chipper knives increase woodroom uptime and give more consistent chip quality. Proceedings of the CPPA $73^{\text {rd }}$ Annual Meeting, Montreal, Canada.

Korobkov, V., 1974: Pneumatic transport and loading of chips. Lesnaya promyshlennost, 174 p. (in Russian).

Krajnc, M., Dolsak, B., 2013: Computer and experimental simulation of biomass production using drum chipper. International Journal f Simulation Models 12(1): 39-49. https://doi. org/10.2507/IJSIMM12(1)4.223

Krausmann, F., Erb, K., Gingrich, S., Lauk, C., Haberl, H., 2008: Global patterns of socioeconomic biomass flows in the year 2000: A comprehensive assessment of supply, consumption and constraints. Ecological Economics 65(3): 471-487. https:// doi.org/10.1016/j.ecolecon.2007.07.012

Liss, J-E., 1987: Power requirement and energy consumption in fuel-chip production using a tractor-mounted chipper. Department of Operational Efficiency, Swedish University of Agricultural Sciences. Licentiate thesis.

Manzone, M., Spinelli, R., 2013: Wood chipping performance of a modified forager. Biomass and Bioenergy 55: 101-106. https://doi.org/10.1016/j.biombioe.2013.01.006

Marchi, E., Magagnotti, N., Berretti, L., Neri, F., Spinelli, R., 2011: Comparing terrain and roadside chipping in Mediterranean pine salvage cuts. Croatian Journal of Forest Engineering 32(2): 587-598. 
Mihelič, M., Spinelli, R., Magagnotti, N., Poje, A., 2015: Performance of a new industrial chipper for rural contractors. Biomass and Bioenergy 83: 152-158. https://doi.org/10.1016/j.biombioe.2015.09.010

Mihelič, M., Spinelli, R., Poje, A., 2018: Production of wood chips from logging residue under space-constrained conditions. Croatian Journal of Forest Engineering 39(2): 223-232.

Moiseev, A., 1981: Wear resistance of wood cutting tools. Lesnaya promyshlennost, 110 p. (In Russian).

Nati, C., Spinelli, R., Fabbri, P.G., 2010: Wood chips size distribution in relation to blade wear and screen use. Biomass and Bioenergy 34(5): 583-587. https://doi.org/10.1016/j.biombioe.2010.01.005

Nati, C., Eliasson, L., Spinelli, R., 2014: Effect of chipper type, biomass type and blade wear on productivity, fuel consumption and product quality. Croatian Journal of Forest Engineering 35(1): 1-7.

Obreshkov, P., 1996: Wood processing machines. Sofia, Bulgaria: Wood Research Institute, 192 p. (In Bulgarian)

Papworth, R., Erickson, J., 1966: Power requirements for producing wood chips. Forest Products Journal 16(10): 31-36.

Pottie, M., Guimier, D., 1985: Preparation of forest biomass for optimal conversion. FERIC Special Report SR-32, Pointe Claire, Canada, 112 p.

Ramos Pires Manso, J., Bashiri Behmiri, N., 2013: Renewable energy and sustainable development. Estudios de Economía Aplicada 31(1): 7-33.

Rawlings, C., Rummer, B., Seeley, C., Thomas, C., Morrison, D., Han, H.-S., Cheff, L., Atkins, D., Graham, D., Windell, K., 2004: A study of how to decrease the costs of collecting, processing and transporting slash. Montana Community Development Corporation, Missoula (MT), 21 p.

Scollard, N., 1980: Throwaway chipper knife saves up to 30\% in operating costs. Pulp \& Paper 54: 181-183.

Spinelli, R., Hartsough, B., 2001: A survey of Italian chipping operations. Biomass and Bioenergy 21(6): 433-444. https://doi. org/10.1016/S0961-9534(01)00050-2

Spinelli, R., Visser, R.J.M., 2009: Analyzing and estimating delays in wood chipping operations. Biomass and Bioenergy 33(3): 429-433. https://doi.org/10.1016/j.biombioe.2008.08.003

Spinelli, R., Magagnotti, N., 2010: A tool for productivity and cost forecasting of decentralised wood chipping. Forest Policy and Economics 12(3): 194-198. https://doi.org/10.1016/j.forpol.2009.10.002

Spinelli, R., Magagnotti, N., 2013: The effect of raw material, cut length, and chip discharge on the performance of an industrial chipper. Forest Products Journal 62(7-8): 58-589. https://doi. org/10.13073/FPJ-D-12-00083.1

Spinelli, R., Magagnotti, N., 2014: Using disposable chipper knives to decrease wood fuel processing cost. Fuel Processing Technology 126: 415-419. https://doi.org/10.1016/j.fuproc.2014.05.026

Spinelli, R., de Arruda Moura, A.C., 2019: Productivity and Utilization Benchmarks for Chain Flail Delimber-Debarkers-Chippers Used in Fast-Growing Plantations. Croatian Journal of Forest Engineering 40(1): 65-80.
Spinelli, R., Hartsough, B., Magagnotti, N., 2005: Testing mobile chippers for chip size distribution. International Journal of Forest Engineering 16(2): 29-35. https://doi.org/10.1080/14942119. 2005.10702511

Spinelli, R., Nati, C., Magagnotti, N., 2007: Recovering logging residue: experiences from the Italian Eastern Alps. Croatian Journal of Forest Engineering 28(1): 1-9.

Spinelli, R., Nati, C., Sozzi, L., Magagnotti, N., Picchi, G., 2011a: Physical characterization of commercial woodchips on the Italian energy market. Fuel 90(6): 2198-2202. https://doi. org/10.1016/j.fuel.2011.02.011

Spinelli, R., Magagnotti, N., Paletto, G., Preti, C., 2011b: Determining the impact of some wood characteristics on the performance of a mobile chipper. Silva Fennica 45(1): 85-95. https:// doi.org/10.14214/sf.33

Spinelli, R., Cavallo, E., Eliasson, L., Facello, A., 2013: Comparing the efficiency of drum and disc chippers. Silva Fennica 47(2): 1-11. https://doi.org/10.14214/sf.930

Spinelli, R., Di Gironimo, G., Esposito, G., Magagnotti, N., 2014a: Alternative supply chains for logging residues under access constraints. Scandinavian Journal of Forest Research 29(3): 266-274. https://doi.org/10.1080/02827581.2014.896939

Spinelli, R., Glushkov, S., Markov, I., 2014b: Managing chipper knife wear to increase chip quality and reduce chipping cost. Biomass and Bioenergy 62: 117-122. https://doi.org/10.1016/j. biombioe.2014.01.007

Spinelli, R., Magagnotti, N., 2014c: Determining long-term chipper usage, productivity and fuel consumption. Biomass and Bioenergy 66: 442-449. https://doi.org/10.1016/j.biombioe.2014.04.016

Spinelli, R., Magagnotti, N., 2014d: Using disposable chipper knives to decrease wood fuel processing cost. Fuel Processing Technology 126: 415-419. https://doi.org/10.1016/j.fuproc.2014.05.026

Spinelli, R., Cavallo, E., Eliasson, L., Facello, A., Magagnotti, N., 2015a: The effect of drum design on chipper performance. Renewable Energy 81: 57-61. https://doi.org/10.1016/j.renene.2015.03.008

Spinelli, R., De Francesco, F., Eliasson, L., Jessup, E., Magagnotti, N., 2015b: An agile chipper truck for space-constrained operations. Biomass and Bioenergy 81: 137-143 https://doi. org/10.1016/j.biombioe.2015.06.017

Spinelli, R., Eliasson, L., Magagnotti, N., 2017: Value retention, service life, use intensity and long-term productivity of wood chippers as obtained from contractor records. Forests 8(12): 503. 13 p. https://doi.org/10.3390/f8120503

Spinelli, R., Eliasson, L., Magagnotti, N., 2019: Determining the repair and maintenance cost of wood chippers. Biomass and Bioenergy 122: 202-210. https://doi.org/10.1016/j.biombioe.2019.01.024

Stampfer, K., Kanzian, C., 2006: Current state and development possibilities of wood chip supply chains in Austria. Croatian Journal of Forest Engineering 27(2): 135-145.

Stokes, B., Watson, W., Sirois, D., Matthes, R., 1987: Factors affecting power requirements for chipping whole trees. ASAE Paper $\mathrm{n}^{\circ}$ 87-6012. Presented at the ASAE Summer Meeting, Baltimore, Maryland, $11 \mathrm{p}$ 
Stupak, I., Asikainen, A., Jonsel, M., Karltun, E., Lunnan, A., Mizaraitė, D., Pasanen, K., Pärn, H., Raulund-Rasmussen, K., Röser, D., Schroeder, M., Varnagirytė, I., Vilkriste, L., Callesen, I., Clarke, N., Gaitnieks, T., Ingerslev, M., Mandre, M., Ozolincius, R., Saarsalmi, A., Armolaitis, K., Helmisaari, H.-S., Indriksons, A., Kairiukstis, L., Katzensteiner, K., Kukkola, M., Ots, K., Ravn, H.P., Tamminen, P., 2007: Sustainable utilisation of forest biomass for energy-Possibilities and problems: Policy, legislation, certification, and recommendations and guidelines in the Nordic, Baltic, and other European countries. Biomass and Bioenergy 31(10): 666-684. https://doi.org/10.1016/j.biombioe.2007.06.012

Tillman, D.A., 1978. Wood as an Energy Resource. Accademic Press, New York, San Francisco, London, 251 p.

Twaddle, A., Watson, W., 1992: Survey of disc chippers in roundwood chipping yards of southeastern United States. TAPPI Journal 75(12): 77-81.

Uhmeier, A., 1995: Some fundamental aspects of wood chipping. Tappi Journal 78(10): 79-86.

Van Belle, J.F., Temmerman, M., Schenkel, Y., 2003: Three level procurement of forest residues for power plant. Biomass and Bioenergy 24(4-5): 401-409. https://doi.org/10.1016/S09619534(02)00161-7

Wegener, J.K., Wegener, T., 2012: The principles of helical chipping - observations based on the construction and use of different prototypes. Applied Engineering in Agriculture 28(4): 491-501. https://doi.org/10.13031/2013.42079
Wegener, J.K., Wegener, T., 2014: Wood chipping with conical helical blades - Theoretical deliberations and practical experiments concerning the adjustment of chip length with a set pitch of the blade. Biomass and Bioenergy 66: 151-158. https://doi. org/10.1016/j.biombioe.2014.01.029

Yingqian, L., Fei, P., 2015: Monitoring Woody Biomass Chips Quality Change during Field Storage in Michigan. Forest Products Journal 65(7-8): 327-336. https://doi.org/10.13073/FPJD-14-00069

Yoshida, M., 2019: Allocation of Mobile Chippers for a Concentrated Bioenergy Demand. Open Journal of Forestry 9(4): 283295. https://doi.org/10.4236/ojf.2019.94016

Yoshioka, T., Aruga, K., Nitami, T., Sakai, H., Kobayashi, H., 2006: A case study on the costs and the fuel consumption of harvesting, transporting, and chipping chains for logging residues in Japan. Biomass and Bioenergy 30(4): 342-348. https:// doi.org/10.1016/j.biombioe.2005.07.013

Young, H.E., Hatton, J.V., 1976: Chipping of tops and branches: a comparison of a drum- and a disk- chipper. Research in Life Sciences 23: 1-11.

Yu, A., Gallagher, T., Mitchell, D., O’Neal, B., 2017: Application of a Small-Scale Equipment System for Biomass Harvesting. Small-scale Forestry 16(1): 133-146. https://doi.org/10.1007/ s11842-016-9347-9

Zamora, R., Sessions, J., Murphy, G., Boston, K., 2013: Economic impact of truck-machine interference in forest biomass recovery operations on steep terrain. Forest Products Journal 63(5-6): 162-173. https://doi.org/10.13073/FPJ-D-13-00031

(C) 2020 by the authors. Submitted for possible open access publication under the terms and conditions of the Creative Commons Attribution (CC BY) license (http://creativecommons.org/licenses/by/4.0/).

Received: December 2, 2019

Accepted: May 2, 2020
Authors' addresses:

Raffaele Spinelli, $\mathrm{PhD}$ *

e-mail: raffaele.spinelli@ibe.cnr.it

CNR IBE

Via Madonna del Piano 10

I-50019 Sesto Fiorentino

ITALY

Prof. Enrico Marchi, PhD

e-mail: enrico.marchi@unifi.it

University of Florence

DAGRI - Department of Agricultural, Food,

Environmental and Forest Sciences and Technologies

Via S. Bonaventura, 13

50145 Florence

ITALY

* Corresponding author 